\title{
The Knowledge Management Processes at Different Stages of Group Development
}

\author{
Ana Pinto ${ }^{1}$ \\ Paulo Renato Lourenço \\ Lisete Mónico \\ Universidade de Coimbra \\ IPCDHS/FPCEUC
}

\begin{abstract}
Based on a developmental approach, this study intended to analyze the extent to which the different stages of group development differ regarding the use of knowledge management processes. The sample comprised 211 teams belonging to a Portuguese military organization. In order to test the hypotheses a multivariate analysis of variance was conducted. The results showed that more mature and cooperative groups (Restructuring/Realization phase) apply to a greater degree the processes of knowledge management, while groups in which there is high intragroup competition and in which members try to "gain power" among themselves (Reframing phase), apply these processes to a lesser degree.
\end{abstract}

Keywords: team knowledge management; group development; work teams

\section{Os Processos de Gestão do Conhecimento nas Diferentes Fases do Desenvolvimento Grupal}

\begin{abstract}
RESUMO - Com base em uma perspetiva desenvolvimental, este estudo analisou em que medida os diferentes estágios de desenvolvimento de um grupo diferem no que diz respeito à utilização dos processos de gestão do conhecimento. O estudo incidiu em uma amostra composta por 211 equipes pertencentes a uma organização militar portuguesa. Para testar as hipóteses formuladas, foi utilizada a análise multivariada da variância. Os resultados revelaram que grupos mais maduros e cooperativos (fase Reestruturação/Realização) aplicam em maior grau os processos de gestão do conhecimento, enquanto grupos em que existe elevada competição intragrupo e em que os membros procuram "ganhar poder" entre si (fase Reenquadramento), aplicam esses processos em menor grau.
\end{abstract}

Palavras chave: gestão do conhecimento nas equipes, desenvolvimento grupal, trabalho em equipes

The literature review which we carried out regarding working groups/teams and knowledge management allows us to affirm that there are advantages in studying them in an articulated way (e.g., Ancona \& Caldwell, 1992; Argote, Ingram, Levine, \& Moreland, 2000; Argote, McEvily, \& Reagans, 2003; Brown \& Utterback, 1985; Henriksen, 2001; Ingram \& Simons, 2002; Jehn \& Shah, 1996; Lee, Gillespie, Mann, \& Wearing, 2010; Liang, Moreland, \& Argote, 1995; Love \& Roper, 2009; Nelson \& Cooprider, 1996; Zárraga \& Bonache, 2003; Zhuge \& Shi, 1997). Indeed, by one side, teamwork constitutes a way of managing and organizing the work which can contribute to increase productivity, quality of work life and ensure high levels of quality of products/ services (Rousseau, Aubé, \& Savoie, 2006). Knowledge management, on the other hand, is nowadays a unique and intangible resource which can be used by groups and organizations in order to acquire advantages regarding competitiveness (Barney, 1991; Miller \& Shamsie, 1996).

Although there is no clear consensus on the concept of team development (Kozlowski, 2015), conceptual and

1 Address for correspondence: Universidade de Coimbra, Rua do Colégio Novo, Coimbra, Portugal. CEP: 3000-15.E-mail: luisa.s.pinto@gmail. com empirical literature about the working groups/teams which adopts a developmental approach (e.g., Buzalo \& Wheelan, 1999; Garfield \& Dennis, 2013; Tuckman \& Jensen, 1977) tend to show that groups change over time and that the group processes/emerging states (e.g., intragroup conflicts, group emotions) operate differently at different levels of group existence (or developmental stages).

Studies carried out in the field of knowledge management in the working groups/teams, (e.g., Ancona \& Caldwell, 1992; Brown \& Utterback, 1985; Cummings, 2004; Huang, 2009; Lee et al., 2010; Prange, 1999; Zhuge \& Shi, 1997), as well as the models that we can find in the literature (e.g., Model of Cardoso and Peralta, 2011; Model of Marin-Garcia and Zarate-Martinez, 2008; Model of Zárraga-Oberty and Garcia Falcón, 2003), do not take into account the group temporality, namely the process of group development. Therefore, the role group development plays in the way the group manages knowledge is not clear in the literature.

With the aim of contributing to a better understanding of the group functioning and also trying to overcome the referred gap in the literature, this study aims to analyze the differences among the different stages of group development regarding 
the degree to which knowledge management processes are applied in a group.

To undertake this study, the Integrated Model of Group Development (IMGD) of Miguez and Lourenço (2001) for group development and the Model of Cardoso and Peralta (2011) for team knowledge management were used as a theoretical and empirical reference.

According to the taxonomy proposed by Chang, Duck, and Bordia (2006), IMGD is comprehensive (it tries to explain group development as an integrated process, accompanying changes occurring in a variety of group settings), generalized (it describes development patterns that can be applied and useful to the study of different types of groups), and path dependent (it takes into account both the individual and group history when explaining group development as a process that occurs through time). The model adopts the socio-technical perspective, with influences of Lewin's Field Theory (1951) and, although inspired by linear models (namely the Wheelan's Integrated Model of Development, 1994), reveals characteristics also present in the cyclic and polar models (Lourenço \& Dimas, 2011b).

The IMGD conceives the group as an "intersubjective reality" founded in two subsystems which are strictly linked to the classical functions of the behaviors of group members (cf. Bales, 1950): the task system and the socio-affective system. Following Lewin, the authors consider the group founded on a tensional forces field - the driving forces and the restraining forces. In order to achieve group emergence and developing, the driving forces must overcome the restraining forces. The basic driving forces, responsible for group emergence, are (a) interdependence, (b) at least one common mobilizing goal and (c) regular relationships among group members according to the goals. With an explicit sociotechnical orientation, the IMGD considers two founding subsystems: the socio-affective system and the task system. These two subsystems are interdependent, highly interactive and are present throughout the entire group life.

Authors such as Wheelan (2005) or Kuipers and Stoker (2009), the IMGD assumes that over time the changes that occur in groups (the dynamic of the founding subsystems) shape distinct phases of group development characterized by different ways of functioning (for example, different levels of intragroup conflict and distinct strategies of conflict handling). In each phase of group development, task and socio-affective dimensions are present and interrelated (Jones \& Bearley, 2001). However, according to the Model, the socio-affective system is dominant in the first stages of development (when the group members are concerned with the inclusion and also with the relationships among them and with the leader) and the task system has a more decisive impact upon the latter stages (when the group is oriented towards increasing both collective and individual contributions in order to achieve the group goals with optimal levels) (Dimas, 2007).

From linear models (e.g., Tuckman \& Jensen, 1977) IMGD adopts the basic structure of a succession of stages (from dependence towards interdependence). From cyclical models (e.g., Karriker, 2005; St. Arnaud, 1978), it includes the notion that groups develop based on advances and setbacks (modelled as a spiral) and that in spite of being functioning in a dominant phase, groups can also show some characteristics of other stages. As a group can return to previous stages - mostly as a consequence of internal or external contingencies, including changes in the group objectives, changes of group members or of leadership, group's eventual fusion, or the fact that a specific task came to its conclusion - the maturity is always temporary.

From polar models (e.g., Smith \& Berg, 1987), the model assumes that the group development is based on a dynamic also built in opposing poles (e.g., dependence vs. independence; group needs vs. individual needs).

The IMGD proposes four development stages Structuring, Reframing, Restructuring and Realization - integrating two distinct development cycles: the socioaffective cycle (including the first two stages) and the task cycle (including the third and fourth stages). While the group is going through the two initial stages, it tends to focus essentially (but not only) on the socio-affective subsystem. By contrast, when the group is going through the last two stages, it tends to focus essentially (but not only) on the task subsystem. In order to progress to the next stage, previous stage issues must be thoroughly settled and satisfactorily solved (Dimas, 2007; Pinto, 2012; Lo, 2011a, 2011b).

In the first moment of group life - structuring - the climate is characterized by some anxiety, as it is a new and undefined situation for group members. The main concern is the inclusion in the group, which is why its members develop efforts to please their peers and the group leader. Dependence regarding the leader, and also the fear of exclusion, lead group members to an initial, careful and defensive exploration, avoiding situations that might result in conflicts. Dependency (of the members to the leader), uniformity (in the sense of conformity to the norms) and inclusion (in the sense of belonging to the group) constitute therefore the keywords to characterize the dominant way of functioning of this initial moment of group life. The inclusion and the sense of belonging marks the moment when the group is ready to moving to the next stage (Rodrigues, 2008).

In the second moment of group life - reframing members seek to assert their individuality. Differences in personality, values and perspectives are potential sources of tension and discord. A climate of high-intensity conflict prevails in which members seek to impose themselves in the group. Counter dependency (a 'no' to dependence of group members vis-à-vis the leader), differentiation (in the sense of distinct individualities) and tension characterize this second phase of group development in a synthetic form. Acceptance of differences marks the moment when the group, after they have "solved" the socio-affective issues that dominate the first development cycle, meets the conditions of transition to the next stage.

In the third moment of group life - restructuring - there emerge higher levels of cooperation and positive involvement from the members to the group. The group is essentially focusing on the task. The integration of group member differences enables more mature strategies for manage key aspects of group life, such as objectives, structure, member roles or performance and well-being. Conflicts are managed primarily through the use of cooperative strategies such as compromise or integration (Dimas, 2007). Normalization [(re) 
defining of functioning rules] and perceived interdependence are keywords to describe this stage (though interdependence is present at all stages of the group development, it is at this stage that the members perceive it more clearly). It is in the context of this perceived and accepted interdependence that the group will reach the maturity that characterizes the subsequent stage.

In the fourth moment of the group life - realization - there is a need to channel most of the energy for fulfilling tasks and for pursuing shared objectives. A climate of confidence, sharing and cooperation prevails, where communication is deep and team activities are facilitated. The perception of interdependence and diversity is seen as an asset and an advantage. Conflicts, when they arise, tend to be managed through the use of integrative strategies (Dimas, 2007; Dimas, Lourenço, \& Miguez, 2008). The fourth phase is the stage of concerted action, high cohesion and functional complicity (Moreira, 2007).

The several empirical studies developed based on the IMDG (e.g., Dimas, 2007; Dimas, Lourenço, \& Miguez, 2008; Ramalho, 2008; Ramalho, Pinto, \& Lourenço, 2012) tend to support its proposals and, overall, IMDG is convergent with the most phase models which assume that mature teams tend to be more effective than teams in early phases of development (Kozlowski \& Ilgen, 2006).

The Model of Cardoso and Peralta (2011), developed for the group level of analysis, was derived from the knowledge management model conceived by Cardoso (2003) for the organizational level. Although the interdependence between knowledge management processes at the group level is common (Liang, Moreland, \& Argote, 1995; Wegner, 1987), according to Cardoso and Peralta (2011), the processes of knowledge management at the organizational level have, in essence, a "correspondence" at the group level. According to the model, there are six dimensions (or processes) of group/ team knowledge management: creation and acquisition of knowledge; attributing meaning to knowledge; sharing and dissemination of knowledge; group memory; recovery and utilization of knowledge, and catalyzers of knowledge management.

We now present the most noteworthy features of each one of the dimensions/processes mentioned:

- Creation and acquisition of knowledge - This is the dimension responsible for all other processes related to group/team knowledge management and it emerges from two sources: internal and external. Sharing ideas, internal training, initiatives that promote and encourage learning and creativity, social interaction and encouragement to collaborate and cooperate are examples of internal sources. Harnessing the knowledge brought to the group/team by new members, and the creation and profitability from various partnerships constitute examples of external sources. Prange (1999) considers that group/team work is a crucial source of competitive advantage since groups have a capacity of building and creating knowledge.

- Attributing meaning to knowledge - This relates to the meaning given by group members to organizational events such as failures, established procedures, routines, successes, norms, etc. It is worth noting that the attribution of meaning to knowledge may vary depending on the characteristics of each group or team.

- Sharing and dissemination of knowledge - This allows knowledge in each working team to spread within the team and through the organization. This process can occur in two distinct forms: in an intentional mode (where the sharing and dissemination of knowledge occurs deliberately and consciously through actions that are explicitly and consciously adopted by different members of the group or team) and in an unintentional mode (of mostly tacit nature, associated with personal experience). The relevance of this process of knowledge management at the group level is highlighted in several studies. For example, Zhuge and Shi (1997) refer that members of a group or team can learn from each other and make more abstractions, analogies, and skills based on experience in problem solving, when there is knowledge sharing. In the same way, Argote et al. $(2000,2003)$ showed that groups/teams who ensure the transfer of knowledge (both internal and external) tend to be more effective and play a key role in the effectiveness of organizations.

- Group memory - This supports and configures storage of a team's knowledge. Group memory can be internal as well as external. The internal group memory is composed by intentional (this is constituted by procedures and routines, as well as by products developed and services provided by the team) and tacit (this refers to the strategy, the policies, the practices of the team, the theories of action, the structure, ecology and culture). The external memory concerns the reputation and the outwardly projected image of the team.

- Recovery and utilization of knowledge - This is a process that can occur in a controlled form or in an automatic form. Controlled recovery can be guided by the team or through technology. Controlled recovery is guided by the team when critical reflection is undertaken about the past group processes which were responsible for success. Controlled recovery is guided by technology when information contained in various organizational repositories is accessed. Automatic recovery mainly encompasses tacit knowledge resulting from the work carried out in accordance with certain values and principles, as well as the conversations held amongst the team. Finally, the utilization of knowledge refers to the instrumentality regarding the development of procedures, processes, services and products.

- Catalyzers - This is a dimension that refers to the stimulus towards completion of different activities of knowledge management, and its optimization. For example, according to Cardoso and Peralta (2011), in a culture focused on learning and knowledge, the encouragement to innovate and to share the knowledge, or the presence of open communication are critical factors that can catalyze knowledge management processes. Considering the developmental approach in which we are placed, as well as the models on which we anchor our research, in this study we expect to find differences in the use of knowledge management processes among the different stages of group development. Phases 3 and 4 tend to be characterized by optimal use of internal and external group resources, by a rich, profound and not defensive communication (involving sharing of information) and by assertiveness and cooperation among the group members, 
as well as an adequate management of task and socioaffective processes. By contrast, in phases 1 (Structuring) and 2 (Reframing) of group development, the group tends to be not able to deal adequately with the difference and complexity and, therefore, tends to not optimize the use of the available resources. Thus, it is expected that in phases 3 and 4 (Restructuring and Realization) the knowledge management processes will be more applied by the group when compared to the less mature phases.

As in phase 2 communication is defensive-aggressive, with low levels of cooperation and high levels of power struggles and competition within the group, the communication tends to be broken and blocked. Consequently, it is also expected that in Phase 2 the knowledge management processes will be less applied when compared to the other group development phases.

Although, as already referred, we have not found studies which have adopted the developmental perspective regarding the group knowledge management processes, the meaning of the differences we expect to find have some support in the literature. In fact, the literature suggests that the groups/teams where the work skills (task and socio-affective) are functional (or, that is, in our words, have acquired greater maturity phases 3 and 4) are also the groups where knowledge is most efficiently managed (e.g., Huang, 2009; Jehn \& Shah, 1996; Lee et al., 2010; Liang et al., 1995; Nelson \& Cooprider, 1996; Prange, 1999; Zárraga \& Bonache, 2003). On the other hand, the characteristics of phase 2 (Reframing) have a tendency to be associated with less efficient knowledge management. To illustrate this, we transcribe what $\mathrm{Yu}$ and Khalifa (2007) have said in this regard:

When the group members assess a strong sense of norms characterized by openness with free-flowing information, tolerance with well-reasoned failure, and pro-social norms emphasizing cooperation, they believe it is desirable to share knowledge within their groups. In contrast, if the norms of a group foster a sense of competition and secrecy, the members would like to withhold rather than share knowledge. (p. 22)

Bresman (2012) corroborates what Yu and Khalifa (2007) defend, though at an inter-team level. The study conducted by that author, in a sample composed by development and research teams of pharmaceutical industry, suggested that competitive relations are negatively associated with knowledge sharing.

Thus, considering the models where we based our study, and also the literature reviewed, the following hypotheses are formulated:

Hypothesis 1: There are significant differences among the phases of group development regarding the level of application of knowledge management processes, expected to be higher in phases 3 and 4 (Restructuring and Realization) when compared to phases 1 and 2 .

Hypothesis 2: There are significant differences among the stages of group development regarding the level of application of knowledge management processes, expected to be lower in phase 2 (Reframing) when compared to phases 1,3 and 4 .

\section{Method}

The study that includes the present research is of a nonexperimental nature (Alferes, 1997), being an ex post facto design. For data gathering, a self-administered questionnaire was used.

\section{Sample}

The sample was composed by 211 teams (2400 participants) from a Portuguese military organization. All districts of Portuguese mainland territory were covered. The teams consisting of a minimum of three and a maximum of thirteen group members $(M=11.4 ; S D=1.5)$. The sample included mostly males ( $95.5 \%$ men and $4.5 \%$ women $)$, with ages ranging from 21 to 56 years $(M=36.5 ; S D=8.2)$. The most represented age group falling between 31 and 35 years, with 560 individuals (24.0\%). Regarding education level, $58.2 \%$ have secondary education. The team members' tenure ranges from one month to 34 years $(M=7.5 ; S D=6.8)$, and 585 respondents $(27.3 \%)$ had been working together for more than one year but not exceeding three years. Considering that the teams in the sample were permanent teams but with rotation of team members along the team existence, the team tenure for each team was measured (in months) considering the oldest tenure in the team. Based on the referred criterion, the team tenure ranged between 13 and 408 months $(M=$ $224.49, S D=84.72$ ).

\section{Measures}

For the measurement of the group development phase of the team (Independent Variable) the GDS scale (Group Development Scale) developed by Pinto in 2009 (published in 2012) and adapted to organizational teams in 2010 by Marques was used. This scale is anchored on the IMGD and, in its original version, was meant to be applied in the context of sports teams. It includes 36 items, distributed across nine categories (communication: type of participation; differences in management; conflict and conflict management; decision-making process; group/team cohesion; existence of subgroups; team norms; roles played by team members within the team; team goals definition). Each category includes four items, corresponding to each one of the four phases proposed by IMGD. In this way, each development phase is measured by 9 items.

The scale of response is Likert-type with seven points, from 1 (Not applicable) to 7 (Totally applicable). Examples of items of the GDS are: "The team members expect that the decisions of the group/team be taken by the leader" (phase 1); "The team members have many different ways of thinking and acting, which leads to misunderstandings and tensions" (phase 2); "The team members begin to participate in the group/team decisions, whenever allowed, trying for the best result for the group/team" (phase 3), and, "There is an atmosphere of complete openness, where participation is encouraged and all listen to and share different opinions in an attempt to integrate them" (phase 4). Both Pinto's studies (2012) and Marques' adaptation (2010) for the working 
groups in organizations, other than sports, revealed that GDS, though capturing only three out of four phases proposed by IMGD (items of phases three and four are grouped together as one factor), had adequate reliability value [the reliability value, using Cronbach's alpha, obtained by Pinto (2012) were: .93 (Structuring phase), .95 (Reframing phase) and .95 (Restructuring/Realization phase); Marques (2010) obtained .68 (Structuring phase), .87 (Reframing phase) and .92 (Restructuring/Realization phase)].

In the present study, exploratory factor analysis and confirmatory factor analysis were conducted. In the analysis of dimensionality through the exploratory analysis, namely principal component analysis, our goal was to verify whether after making adjustments to the writing of some items of phase 3 (Restructuring) and phase 4 (Realization) the fourdimensional structure would emerge. For the exploratory analysis, about $30 \%$ of the individuals from the collected total sample were selected at random. The structure that emerged was three-dimensional (phase $1=$ Structuring; phase $2=$ Reframing; phase 3/4 = Restructuring/Realization), similarly to the studies carried out by Pinto (2012) and Marques (2010). Factor 3/4 (Restructuring/Realization) was composed by 14 items (loadings ranging from .63 to .80); factor 2 (Reframing) included 8 items, (loadings between .71 and .79), and factor 1 (Structuring), included 3 items (loadings between .65 and $.81)$. The reliability values obtained, through Cronbach's alpha, were .94 for phase 3/4 (Restructuring/Realization), .90 for phase 2 (Reframing) and .65 for phase 1 (Structuring).

After Confirmatory Factor Analysis (CFA) (using a sample composed by $70 \%$ of the individuals from the collected total sample) we remained with a total of 25 items ( 3 items related to Structuring; 8 related to Reframing and 14 related to Restructuring/Realization). We obtained the following fit indices of CFA, which, following the reference values proposed by Brown (2006), and also Kline (2011), indicated a good model fit: Standardized Root Mean Square Residual (SRMR) $=.04 ;$ Root Mean Square Error of Approximation (RMSEA) $=.05 ;$ Comparative Fit Index (CFI) $=.94 ;$ Tucker-Lewis Index $(\mathrm{TLI})=.93$.

The reliability analysis pointed to satisfactory results. In fact, the alpha values were $.68, .91$ and .93 for the Structuring, Reframing, and Restructuring/Realization dimensions, respectively. It should be noted that, considering the threedimensional structure of the GDS, the test to verify our hypotheses was conducted using phases 1, 2 and 3/4.

For the dependent variable, the KMT scale (Knowledge Management Team) by Cardoso and Peralta (2011) was used. The KMT is anchored on Cardoso's Model (2003) inspired by different theoretical contributions (American, Japanese and European theoretical guidelines) - and results from an adaptation and operationalization of the organizational level items to the group level. The KMT scale has 88 items and allows us to evaluate fourteen processes of team knowledge management distributed among six sections: creation and acquisition of knowledge (internal -6 items; external - 6 items), attribution of meaning ( 7 items), sharing and dissemination of knowledge (intentional -8 items; unintentional -6 items), team memory (internal and intentional memory -6 items; internal and tacit memory -7 items; external memory -6 items), recovery and utilization of knowledge (controlled recovery - 6 items; automatic recovery -6 items; utilization -6 items) and knowledge management catalyzers (leader -6 items; members -6 items; organization -6 items). The scale of response is a Likert-type scale with 5 points, ranging from $1=$ (Hardly applicable or Not applicable) to $5=$ (Almost totally applicable or totally applicable). Examples of some of the items that are part of the KMT scale are: "Knowledge of each member is important", "The members share their know-how", "We know intuitively how to act within our team", "We discuss the rules that regulate our functioning", "We carry out part of our work intuitively."

Cardoso and Peralta (2011) analyzed the one-dimensional aspect of each of the fourteen processes through exploratory factor analysis. All the processes were one-dimensional and all factor loadings were greater than or equal to .40. The reliability, estimated through Cronbach's alpha showed an $\alpha=.956$ for global scale and, for all the processes of team knowledge management, Cronbach's alpha ranged between .71 (automatic recovery process) and .94 (catalyzer team leader).

In our research the catalyzers of knowledge management were not used since our interest was in studying the knowledge management processes and the catalyzers are just stimulators of the referred processes. The KMT scale which we used and which was subject to confirmatory analysis studies contained 70 items.

After Confirmatory Factor Analysis (CFA) we were left with 53 items (4 items for creation and external acquisition process, 3 items for creation and internal acquisition process, 3 items for the automatic recovery process, 6 items for the process of attribution of meaning to knowledge, 7 items for the sharing and intentional dissemination process, 4 items for the sharing and unintentional dissemination process, 6 items for the internal and intentional memory process, 6 items for the internal and tacit memory process, 5 items for the external memory process, 5 items for the controlled recovery process and 4 items for utilization of knowledge process). Average Fit Indices of CFA were: $\mathrm{SRMR}=.02 ; \mathrm{RMSEA}=.06 ; \mathrm{CFI}=$ .99 , and TLI $=.97$. The values of Cronbach's alpha, ranged from .70 (Creation and external acquisition process) and .89 (Utilization of knowledge process).

\section{Data Collection Procedures}

In the military organization where the research was conducted, the work is based on teams corresponding to the conception of team/group we adopt (Miguez \& Lourenço, 2001): (a) the team is composed at least by three elements; (b) the members are recognized and recognize themselves as a team, and, (c) they would interact regularly and interdependently in order to reach a common goal.

Data collection was conducted between January and June of 2011. We included in our study all the districts of the Portuguese mainland territory (eighteen districts in total), and, in each district, questionnaires were collected from twelve territorial stations (each territorial unit represents a group/team). The criterion of choosing the territorial stations was carried out by the military organization on a 
completely random basis. Within each territorial unit, team members were asked to complete two scales, which were used to measure group development and team knowledge management. Since in each territorial unit the data was collected by a member of the military organization (not belonging to the sampling teams) who, therefore, liaised closely with the research team, we were careful in instructing each collaborator about what procedures should be followed. Envelopes with the team code (territorial unit) were prepared and distributed among the territorial units, and each envelope carried in it questionnaires meant to be answered (that were also codified in order to ensure the confidentiality of the data collection).

The participation in the study was voluntary. All participants provided their informed consent and the confidentiality and the anonymity were guaranteed by the research team. The research team also clarified that only aggregated data would be reported and that all identifying information would be removed.

\section{Data Analysis}

Data was processed in IBM SPSS Statistics and AMOS 22.0. Missing values $(<5 \%)$ were all MCAR and replaced through the Expectation Maximization Method (Ibrahim, Chen, Lipsitz, \& Herring, 2005). The existence of outliers was evaluated by the square distance of Mahalanobis (Tabachnick \& Fidell, 2013) and normality of the variables was evaluated by the coefficients of asymmetry (Sk) and kurtosis $(\mathrm{Ku})$. No significant outliers were registered and, considering we obtained $|\mathrm{Sk}|<0.641$ and $|\mathrm{Ku}|<1.06$, none of the variables indicated violations of normal distribution (Shapiro-Wilk univariate tests with $p>.05$ ).

After the descriptive statistics and intercorrelation matrix, the data were analyzed through a multivariate analysis of variance (MANOVA, General Linear Model procedure; Hair, Anderson, Tatham, \& Black, 2008), fulfilling the required assumptions for the reliable use of this test, namely: a) Independence of observations; b) Normality of distribution within each group with $\mathrm{n}<30$ observations (reframing phase; Shapiro-Wilk test showed normal distribution for all KMT dimensions, $\mathrm{p}>$ > 251); c) Homogeneity of error variances; this assumption was evaluated with Levene's test of equality of error variances, showing that the error variance was equal across groups for all dependent variables $(p>.248)$.

Post-hoc Fisher's LSD tests for multiple comparisons were performed, since the independent variable has three levels (Alferes, 1997, p. 142). A significance level of $\alpha=.05$ for Type I error for all the analyses was considered. Effect sizes of correlations (low, medium, or high correlations) were classified according to Cohen (1988). Magnitude of the experimental effect was obtained by calculating eta squared (†2) measure (Howell, 2013).

\section{Intragroup Agreement and Intergroup Heterogeneity}

Since the focus of the study is at the group level and the information was collected individually, the data were aggregated by calculating the average scores obtained by team members in the instruments used. To justify this aggregation, the $\mathrm{AD}$ Index was calculated (Average Deviation Index; Burke, Finkelstein, \& Dusing, 1999; Burke \& Dunlap, 2002). For that, the ratio $\mathrm{c} / 6$ proposed by Burke and Dunlap (2002), where "c" stands for the number of response options for the items of each measuring instrument, was used. For the GDS and KMT scales the ratios obtained were 1.17 and .83 respectively. Since the average values of the indices of agreement ADM for the GDS and KMT scales were, respectively, $1.01(\mathrm{SD}=.26$; minimum $=.00$, maximum $=1.83)$ and $.76(\mathrm{SD}=.18 ;$ minimum $=.00$, maximum $=$ 1.11), below the values established for the cut-off points, similarly to Gamero, Gonzalez-Romá and Peiró (2008), we conclude that the intragroup level of agreement is sufficient to aggregate the individual scores.

To assess inter-team heterogeneity, we made use of the one way analysis of variance (ANOVA) and the effect size (Cohen, 1988), calculated through eta-square $(\eta 2)$. This calculation took place on an individual basis, taking as Independent Variable (VI) the team, in a total of 211 levels (211 teams), and as Dependent Variable (VD) the average score, in each of the scales (GDS and KMT).

For the GDS scale, ANOVA pointed to an $F(210,1969)$ $=1.97, p<.001$, which shows us that there is an inter-team differentiation regarding the different stages of group development. The value of the eta-square $(\eta 2=.173)$ reveals an effect size of $17.3 \%$. For the KMT scale, ANOVA pointed to an $F(210,1969)=2.49, p<.001$ and the values of effect size pointed to $21.0 \%$ of variability of the KMT scale (total). These results show an adequate inter-team discrimination supporting the validity of data aggregation of the measures used (Chan, 1998).

The intra-class correlation coefficients ICC(1) and ICC(2) were obtained for all measures in each team. The ICC(1) aims to estimate the proportion of variance that is explained by group membership (Bryk \& Raudenbush, 1982) and the ICC(2) estimates the reliability of the group means (Bliese, 2000).

The ICC(1) scores obtained ranged between .05 (95\% CI from .02 to .11) and $.79(95 \%$ CI from .69 to .86), with a median of .22 , and $M=.23$ and $S D=.10$. James (1982) reviewed some empirical studies and found that ICC(1) usually varied between .00 and .50 , with a median score of .12 (p. 224) and Bliese (2000) typically found values between .05 and .20 (p. 360).

For ICC(2), according to Klein and Kozlowski (2000), values higher than .50 are acceptable and values higher than .70 are considered good. The ICC(2) scores in this research ranged between .38 (95\% CI from .15 to .56) and .95 (95\% CI from .93 to .97$)$, with a median of .75 , and $M=.72$ and $S D$ $=.11$. From the 211 teams, only two obtained ICC(2) scores lower than .40 and nine scored between .40 and .50 . The remaining 200 scored above .50 (and 138 scores above .70).

Considering the results obtained with the referred procedures, based on ADM and ICCs scores, we conclude for the support of the data aggregation to the team level ( $\mathrm{N}$ $=211$ teams). 


\section{Identification of the Phase of Group Development}

In order to identify in which phase of group development a team should be placed, we resorted to the average score of each team in each of the three phases (phase 1 - Structuring, phase 2 - Reframing, and phase 3/4 -Restructuring/ Realization). The highest score in any of the three phases would indicate in which phase a team would be placed. In order to increase accuracy in phase identification, each team was placed at a certain phase, only in the situation where the highest average score (the one that identified the development phase) was at least 10\% higher than each of the other phases. Since in the 27 teams a difference of at least $10 \%$ between the most punctuated phase and the remaining phases was not registered, these teams were eliminated given that they were not discriminative in relation to one of the phases. The total sample was left with 184 teams, 52 in phase 1,16 in phase 2 and 116 in phase $3 / 4$. The unbalanced distribution of teams in the group development phases is not surprising. In fact, the average team tenure is high $(\mathrm{M}=224.49$ months $)$, increasing the probability that most groups will be in high maturity phases $(63.0 \%)$. In addition, teams in military organizations may tend to operate on the basis of high conformity and to be highly focused on their leader, which explains the relatively high percentage of teams in stage one $(28.3 \%)$ and the low percentage of teams in stage two $(8.7 \%)$.

\section{Results}

Both measures, GDS and KMT were analyzed concerning the means $(M)$, standard-deviations $(S D)$, and intercorrelations (Pearson's r, see Table 1). Considering the mean scores, teams are mostly in phases 3 and 4 (Restructuring/Realization), followed by phase 1 (Structuring) and, at last, phase 2 (Reframing). Utilization of knowledge was the KMT dimension with the highest score, followed by Creation and internal acquisition and Internal and tacit memory. Automatic recovery received the lowest score.

Attributing meaning to knowledge, Sharing and intentional dissemination, Internal and tacit memory, and Controlled recovery, are highly associated with KMT global scale ( $r$ of .90 and .91). The same occur with Internal and intentional memory, External memory, and Sharing and unintentional dissemination ( $\mathrm{r}$ between .80 and .86) and the remaining factors, with correlations above .50 . These results suggest that, although factors represent different dimensions of KMT, all are related to a common construct of knowledge management. With exception to Automatic recovery, whose correlation is low ( $r=.28 ; 7.8 \%$ of shared variance).

Structuring and Reframing were positive and moderately associated. The correlation between Structuring and Restructuring/Realization was positive and low, and the association between Reframing and Restructuring/ Realization was negative and high. Overall, the correlation of the majority of KMT dimensions are positive and high with Restructuring/Realization phase (exception for Automatic recovery, with a null correlation), positive and low with Structuring phase, and negative and moderate with Reframing phase. Team tenure was only significantly associated (negative correlation) with Creation and external acquisition, despite this correlation being low.

To test Hypotheses 1 and 2, we proceeded with a multivariate analysis of variance (MANOVA, General Linear Model procedure) taking the predominant phase of the team ( 1 = Structuring; 2 = Reframing; $3 / 4$ =Restructuring/ Realization) as Independent Variable (IV) and the average scores obtained on a global scale and in the eleven KMT questionnaire processes as Dependent Variables (DVs).

The analysis of multivariate test indicates that the overall effect is statistically significant, with Wilk's $\Lambda=.702, F(22$, $342)=3.01, p<.001, \eta 2=.162$ (effect size of $16.2 \%$ ). When we consider the eleven processes in their specificity, we find differences between the three phases of group development for all the processes, with the exception of Creation and external acquisition, External memory and Automatic recovery (see Table 2). Higher effect sizes are found in Sharing and intentional dissemination (13.7\%), Utilization of knowledge and Internal and tacit memory (both with an effect size of $12.7 \%$ ).

By undertaking Fisher's LSD multiple comparison tests, we achieved the goal of identifying the differences between the three phases of group development as regards the global scale and the eleven KMT processes. The results are indicated in Table 3.

As it is shown, there are statistically significant differences between the three phases of group development on the KMT global scale. In particular, the processes of team knowledge management as a whole apply less at the Reframing phase than at the Structuring and Restructuring/Realization phases. On the other hand, knowledge management processes apply more at the Restructuring/Realization phase, outshining distinctly the KMT's global score at this phase compared to the Reframing phase, though also at the Structuring phase. The results indicate the expected direction.

With regard to each of the knowledge management processes, the differences between the phase 2 (Reframing) and the phases 3 and 4 (Restructuring/Realization) appear to be the most significant ones, where one can highlight a greater degree of application of team knowledge management processes of phases 3 and 4 (Restructuring/Realization) in comparison to what was found in phase 2 . The most pronounced difference between phase 2 (Reframing) and phases 3 and 4 (Restructuring/Realization) is identified in the processes of Sharing and intentional disseminating of knowledge, Utilization of knowledge and Creation and internal knowledge acquisition. It should be noted that some differences between phase 2 (Reframing) and the other phases may not be significant due to the reduced number of teams at stage $2(n=16)$ in comparison with phase $1(n=52)$ and phase $3 / 4(n=116)$.

The average scores of the KMT processes depending on the phases of group development are represented graphically in Figure 1. The graphical representation was ordered from the greatest mean values of knowledge management processes to the lowest mean values. Overall, one can highlight the lowest scores in phase 2 (Reframing) and the highest scores in the phase 3/4 (Restructuring/Realization). 


\section{Discussion}

Although we have formulated general hypotheses (H1 and H2), whenever it is deemed appropriate, we will devote attention to the results for each of the knowledge management processes evaluated.
The results obtained in the research carried out showed significant differences among the group development phases regarding the level of application of knowledge management processes considered as a whole. The processes of team knowledge management are applied to a greater degree in phases 3 and 4 (Restructuring/Realization) compared to phase 1 (Structuring) and 2 (Reframing), and applied to a lesser

Table 1. Descriptive statistics and correlation matrix between GDS and KTM [N=211 teams]

\begin{tabular}{|c|c|c|c|c|c|c|c|c|c|c|c|c|c|c|c|c|c|c|}
\hline & M & SD & 1 & 2 & 3 & 4 & 5 & 6 & 7 & 8 & 9 & 10 & 11 & 12 & 13 & 14 & 15 & 16 \\
\hline Structuring (1) & 4.28 & .45 & 1.00 & $.31^{* *}$ & $.15^{*}$ & $.22 * *$ & $.22 * *$ & $.16^{*}$ & $.18^{*}$ & $.19^{* *}$ & $.20 * *$ & $.20^{* * *}$ & .13 & $.21 * *$ & $.19^{* *}$ & $.17^{*}$ & .07 & .03 \\
\hline Reframing (2) & 3.51 & .50 & & 1.00 & $-.52 * *$ & $-.21 * *$ & .01 & $-.30^{* *}$ & $-.25^{* *}$ & $-.27 * *$ & -.12 & $-.25 * *$ & $-.31 * *$ & -.04 & $-.18 * *$ & $.40^{* *}$ & $-.33 * *$ & -.05 \\
\hline \multicolumn{19}{|l|}{ Restructuring/ } \\
\hline Realization (3/4) & 4.63 & .40 & & & 1.00 & $.65 * *$ & $.37 * *$ & $.58^{* *}$ & $.61^{* *}$ & $.66^{* *}$ & $.44^{* *}$ & $.50^{* *}$ & $.68 * *$ & $.48^{* *}$ & $.57 * *$ & -.04 & $.53^{* *}$ & .03 \\
\hline $\begin{array}{l}\text { KMT - global } \\
\text { scale (4) }\end{array}$ & 3.50 & .25 & & & & 1.00 & $.69 * *$ & $.72 * *$ & $.90^{* *}$ & $.90^{* *}$ & $.80^{* *}$ & $.86 * *$ & $.91 * *$ & $.82 * *$ & $.90^{* *}$ & $.28^{* *}$ & $.72 * *$ & .01 \\
\hline $\begin{array}{l}\text { Creation and external } \\
\text { acquisition (5) }\end{array}$ & 3.09 & .32 & & & & & 1.00 & $.32 * *$ & $.54^{* *}$ & $.69^{* *}$ & $.54^{* *}$ & $.55^{* * *}$ & $.47^{* *}$ & $.63^{* *}$ & $.60^{* *}$ & $.36^{* *}$ & $.20^{* *}$ & $-.15^{*}$ \\
\hline $\begin{array}{l}\text { Creation and internal } \\
\text { acquisition (6) }\end{array}$ & 3.99 & .32 & & & & & & 1.00 & $.66^{* *}$ & $.60^{* *}$ & $.58^{* *}$ & $.57^{* *}$ & $.72 * *$ & $.47^{* *}$ & $.64 * *$ & -.03 & $.73^{* *}$ & .09 \\
\hline $\begin{array}{l}\text { Attributing meaning } \\
\text { to knowledge (7) }\end{array}$ & 3.57 & .30 & & & & & & & 1.00 & $.79 * *$ & $.69 * *$ & $.75^{* *}$ & $.84 * *$ & $.69^{* *}$ & $.79 * *$ & $.16^{*}$ & $.69 * *$ & .05 \\
\hline $\begin{array}{l}\text { Sharing and } \\
\text { intentional } \\
\text { dissemination (8) }\end{array}$ & 3.31 & .31 & & & & & & & & 1.00 & $.71^{* *}$ & $.74 * *$ & $.77^{* *}$ & $.68^{* *}$ & $.78^{* *}$ & $.22 * *$ & $.53 * *$ & -.01 \\
\hline $\begin{array}{l}\text { Sharing and } \\
\text { unintentional } \\
\text { dissemination (9) }\end{array}$ & 3.51 & .31 & & & & & & & & & 1.00 & $.65^{* *}$ & $.69^{* *}$ & $.58^{* *}$ & $.65^{* *}$ & $.20 * *$ & $.54 * *$ & -.03 \\
\hline $\begin{array}{l}\text { Internal and } \\
\text { intentional memory } \\
\text { (10) }\end{array}$ & 3.47 & .28 & & & & & & & & & & 1.00 & $.78 * *$ & $.71^{* *}$ & $.75^{* *}$ & .13 & $.62 * *$ & .08 \\
\hline $\begin{array}{l}\text { Internal and tacit } \\
\text { memory (11) }\end{array}$ & 3.65 & .29 & & & & & & & & & & & 1.00 & $.71^{* *}$ & $.79 * *$ & .10 & $.78^{* *}$ & .02 \\
\hline External memory (12) & 3.38 & .30 & & & & & & & & & & & & 1.00 & $.71^{* *}$ & $.31^{* *}$ & $.46^{* *}$ & -.02 \\
\hline $\begin{array}{l}\text { Controlled recovery } \\
\text { (13) }\end{array}$ & 3.54 & .28 & & & & & & & & & & & & & 1.00 & $.24^{* *}$ & $.65^{* *}$ & .05 \\
\hline $\begin{array}{l}\text { Automatic recovery } \\
\text { (14) }\end{array}$ & 2.94 & .35 & & & & & & & & & & & & & & 1.00 & -.11 & -.10 \\
\hline $\begin{array}{l}\text { Utilization of } \\
\text { knowledge (15) }\end{array}$ & 4.06 & .36 & & & & & & & & & & & & & & & 1.00 & .07 \\
\hline $\begin{array}{l}\text { Team Tenure in } \\
\text { months }(16)\end{array}$ & 224.91 & 84.72 & & & & & & & & & & & & & & & & 1.00 \\
\hline
\end{tabular}

Table 2. Average Scores and Standard Deviations of the KMT Scale Processes in Accordance with the Three Phases of Group Development: Multivariate Analysis of Variance (F Ratios) and Effect Size ( $\eta 2)$

\begin{tabular}{|c|c|c|c|c|c|c|c|c|}
\hline \multirow{3}{*}{ KMT-global scale } & \multicolumn{2}{|c|}{$\begin{array}{l}\text { Structuring } \\
\quad(\mathrm{n}=52)\end{array}$} & \multicolumn{2}{|c|}{$\begin{array}{l}\text { Reframing } \\
(\mathrm{n}=16)\end{array}$} & \multicolumn{2}{|c|}{$\begin{array}{c}\text { Restructuring/ } \\
\text { Realization }(n=116)\end{array}$} & \multirow{3}{*}{$\mathrm{F}(2,181)$} & \multirow{3}{*}{$\eta 2$} \\
\hline & $M$ & $S D$ & $M$ & $S D$ & $M$ & $S D$ & & \\
\hline & 3.47 & .24 & 3.27 & .29 & 3.55 & .23 & & \\
\hline Creation and external acquisition & 3.14 & .32 & 2.96 & .33 & 3.11 & .32 & 1.97 & .021 \\
\hline Creation and internal acquisition & 3.94 & .29 & 3.69 & .36 & 4.07 & .30 & $12.45 * * *$ & .121 \\
\hline Attributing meaning to knowledge & 3.50 & .30 & 3.34 & .33 & 3.65 & .27 & $11.36 * * *$ & .112 \\
\hline Sharing and intentional dissemination & 3.27 & .31 & 2.97 & .34 & 3.39 & .30 & $14.39 * * *$ & .137 \\
\hline Sharing and unintentional dissemination & 3.51 & .32 & 3.29 & .30 & 3.56 & .29 & $5.78 * *$ & .060 \\
\hline Internal and intentional memory & 3.47 & .28 & 3.25 & .33 & 3.52 & .27 & $6.89 * *$ & .071 \\
\hline Internal and tacit memory & 3.58 & .27 & 3.39 & .31 & 3.72 & .27 & $13.17 * * *$ & .127 \\
\hline External memory & 3.39 & .32 & 3.24 & .33 & 3.41 & .30 & 2.29 & .025 \\
\hline Controlled recovery & 3.52 & .27 & 3.28 & .37 & 3.59 & .27 & $8.66 * * *$ & .087 \\
\hline Automatic recovery & 3.01 & .38 & 2.98 & .40 & 2.90 & .31 & 1.85 & .020 \\
\hline Utilization of knowledge & 3.95 & .35 & 3.78 & .46 & 4.16 & .32 & $13.13 * * *$ & .127 \\
\hline
\end{tabular}


degree in phase 2 (Reframing) compared to the other phases (phase 1 - Structuring and phases 3 and 4 - Restructuring/ Realization). These results are in tune with what we expected, to empirically support the hypotheses formulated, and are interpretable in the light of the Integrated Model of Group Development of Miguez and Lourenço (2001) on which we based our study.

It is expected that at the phase of greater group maturity, phases 3 and 4 (Restructuring/Realization), knowledge management processes will bring together the best conditions for them to be applied. In this phase, the group climate is

Table 3. Differences Between the Averages and Standard Errors (in brackets) of the KMT Scale and Constituent Processes Depending on the Phases of Group Development: Fisher's LSD Multiple Comparison Tests

\begin{tabular}{|c|c|c|}
\hline & \multicolumn{2}{|c|}{ Phases of group development (GDS) } \\
\hline & Reframing (2) & Restructuring/Realization (3/4) \\
\hline & \multicolumn{2}{|c|}{ Differences between the averages (KMT) } \\
\hline GDS & \multicolumn{2}{|c|}{ KMT - global scale } \\
\hline Structuring (1) & $.202 * *(.07)$ & $-.081 *(.04)$ \\
\hline \multirow[t]{2}{*}{ Reframing (2) } & - & $-.283 * * *(.06)$ \\
\hline & \multicolumn{2}{|c|}{ KMT - constituent factors } \\
\hline GDS & \multicolumn{2}{|c|}{ Creation and external acquisition } \\
\hline Structuring (1) & $.180 *(.09)$ & $.031(.05)$ \\
\hline \multirow[t]{2}{*}{ Reframing (2) } & - & $-149(.09)$ \\
\hline & \multicolumn{2}{|c|}{ Creation and internal acquisition } \\
\hline Structuring (1) & $.251 * *(.09)$ & $-.129 *(.05)$ \\
\hline \multirow[t]{2}{*}{ Reframing (2) } & - & $-.380 * * *(.08)$ \\
\hline & \multicolumn{2}{|c|}{ Attributing meaning to knowledge } \\
\hline Structuring (1) & $.161 *(.08)$ & $-.151^{* *}(.05)$ \\
\hline \multirow[t]{2}{*}{ Reframing (2) } & - & $-.312 * * *(.08)$ \\
\hline & \multicolumn{2}{|c|}{ Sharing and intentional disseminating } \\
\hline Structuring (1) & $.295^{* *}(.09)$ & $-.122 *(.05)$ \\
\hline \multirow[t]{2}{*}{ Reframing (2) } & - & $-.417 * * *(.08)$ \\
\hline & \multicolumn{2}{|c|}{ Sharing and unintentional dissemination } \\
\hline Structuring (1) & $.219 *(.09)$ & $-.05(.05)$ \\
\hline \multirow[t]{2}{*}{ Reframing (2) } & - & $-.269^{* *}(.08)$ \\
\hline & \multicolumn{2}{|c|}{ Internal and intentional memory } \\
\hline Structuring (1) & $.225^{* *}(.08)$ & $-.05(.05)$ \\
\hline \multirow[t]{2}{*}{ Reframing (2) } & - & $-.274 * *(.07)$ \\
\hline & \multicolumn{2}{|c|}{ Internal and tacit memory } \\
\hline Structuring (1) & $.195 *(.08)$ & $-.140 * *(.05)$ \\
\hline \multirow[t]{2}{*}{ Reframing (2) } & - & $-.335 * * *(.07)$ \\
\hline & \multicolumn{2}{|c|}{ External memory } \\
\hline Structuring (1) & $.154(.09)$ & $-.022(.05)$ \\
\hline \multirow[t]{2}{*}{ Reframing (2) } & - & $-.176 *(.08)$ \\
\hline & \multicolumn{2}{|c|}{ Controlled recovery } \\
\hline Structuring (1) & $.238 * *(.08)$ & $-.066(.05)$ \\
\hline \multirow[t]{2}{*}{ Reframing (2) } & - & $-.305 * * *(.07)$ \\
\hline & \multicolumn{2}{|c|}{ Automatic recovery } \\
\hline Structuring (1) & $.032(.10)$ & $-.106(.06)$ \\
\hline \multirow[t]{2}{*}{ Reframing (2) } & - & $.07(.09)$ \\
\hline & \multicolumn{2}{|c|}{ Utilization of knowledge } \\
\hline Structuring (1) & $.171(.10)$ & $-.212 * * *(.06)$ \\
\hline Reframing (2) & - & $-.382 * * *(.09)$ \\
\hline
\end{tabular}

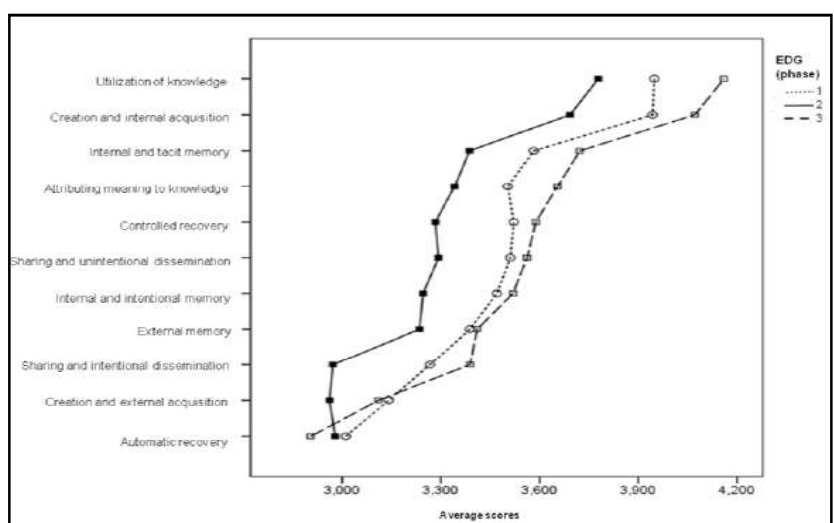

Figure 1. Average scores of the KMT scale processes depending on the three phases of group development

characterized by open communication; trust among team members and between team members and the leader, deep and stable relations, cooperation, organized structure, "functional" cohesion, and also by mutually accepted and shared rules, as well as by a high capacity of the group to deal with the complexity of the environment in which it operates. In our sample (teams of a military organization) and in a more detailed analysis, we can ascertain that the majority of the knowledge management processes lie in this situation, as can be seen by the higher scores showed by the teams in Restructuring/Realization phase when compared to Structuring phase (Creation and internal acquisition, Attributing meaning to knowledge, Sharing and intentional dissemination, Internal and tacit memory, and Utilization of knowledge).

Despite being limited (as already mentioned), the literature supports our results. In fact, these processes of team knowledge management - in particular, the process of sharing and intentional dissemination - are referred to as being more applicable to groups with a higher degree of maturity (Huang, 2009; Jehn \& Shah, 1996; Liang et al., 1995; Nelson \& Cooprider, 1996; Prange, 1999; Wegner, 1987).

On the other hand, the characteristics of phase 2 (Reframing) provide an environment that allows the use of knowledge management processes to a lesser degree. In this phase, there tends to be weak cohesion (maximum forces of disintegration), tension (tension, deception, contestation, counterdependency vis-à-vis the leader's authority). Also the dynamic of the socio-affective system marked by "tempestuous" relations and misunderstandings of communication, competitive participation and existence of subgroups in opposition contributes to build a context where the team resources, including knowledge, tend to not to be sufficiently applied and adequately used. Similarly to $\mathrm{H} 1$, when we carry out a more detailed analysis regarding $\mathrm{H} 2$, we can see that most of the knowledge management processes are less applied at stage two, in comparison to the other stages. Indeed, we found lower scores in Reframing phase in comparison with Structuring and Restructuring/ Realization concerning creation and internal acquisition process, attributing of meaning, sharing and intentional dissemination, sharing and unintentional dissemination, internal and intentional memory, internal and tacit memory, and controlled recovery. Additionally, teams in Reframing phase showed lower scores in comparison with teams 
in Structuring phase concerning Creation and external acquisition, and lower scores in comparison with teams in Restructuring/Realization phase concerning External Memory and Utilization of knowledge. These results are convergent with the conclusions made by $\mathrm{Yu}$ and Khalifa (2007) who defend that groups with the characteristics that we find in the phase 2 (Reframing) tend to be associated with less efficient knowledge management, in particular relating to sharing of knowledge.

The sharing and intentional dissemination process is the one in which there is the greatest difference between the average of phases 3 and 4 (Restructuring/Realization) and the average of phase 2 (Reframing). Similarly, this process - intended sharing and intentional dissemination presents the greatest difference between the average of phase 1 (Structuring) and the average of phase 2 (Reframing). We can therefore conclude that the sharing and intentional dissemination process, one of the processes that is the least applied in phase 2, is the one in which phase 2 (Reframing) differs from the other two phases more clearly. This process is very sensitive to the set of behaviors that are likely to facilitate the implementation of common tasks within the teams - e.g., cooperation, communication, psychological support, conflict management, planning/work organization, management of resources and support for innovation (Rousseau, Aubé, \& Savoie, 2006). In phase 2 (Reframing), the dominant competition climate will tend to inhibit cooperative behaviors based on sharing and dissemination of information and knowledge.

The creation and external acquisition process, external memory process, and automatic recovery process, operate similarly in phase 1 (Structuring), in phase 2 (Reframing) and in phase $3 / 4$ (Restructuring / Realization). In our view, the type of sample we used in this study - groups/teams of a military organization - can help to understand these results. The creation and external acquisition process is one of the processes that least applies in the teams studied in our sample. In teams characterized by very hierarchical and highly formal procedures, the norm is that new members must somehow be "submissive" (and therefore the knowledge they could bring into the team is ignored). In these kinds of teams the team members' tenure gives him a high status. Team members with high status tend to be more heard and to exercise greater influence than the members of the team with lower status. This fact can explain why this process does not seem to depend on the development phase, but on the team tenure. Thus, regarding creation and external acquisition processes, the temporal dimension of the team seems to be more important than the team development level. As we have noted, the only negative and significant correlation $(r$ $=-15$ ) with team tenure is precisely regarding creation and external acquisition. The external memory process refers to the reputation and image that the team projects to the outside, through the interactions it establishes with the other teams of the organization, as well as the information recorded about the team, in diverse organizational documents. This is an unexpected result which is difficult to explain, but despite the fact that, although no significant differences have been obtained, the highest average in this process is in stage $3 / 4$
(3.41), followed by the stage 1 (3.29), the lowest being that of stage 2 (3.24) (although it does not reach statistical significance, it accompanies what, conceptually, would make sense, showing a trend). On the other hand, the correlations between External Memory and phases are positive and significant with phases 1 and 3/4 - and not with phase 2 . The automatic recovery process expresses the lowest average scores of all the processes of team knowledge management, in each one of the phases (phase 1, phase 2 and phase 3/4). Some of the items that make up the automatic recovery process (e.g., "'We execute tasks without thinking about the knowledge that we are applying") have a lower relevance in our sample. The applied knowledge in the working context of the military organization is knowledge that is properly regulated and legislated, and which "requires" that the team members be highly aware of all norms and procedures when they are in action.

Finally, it is important to highlight that the average scores of the KMT global scale obtained in phase 1 (Structuring), 2 (Reframing) and 3/4 (Restructuring/Realization), in our sample, are situated above 3 points on a scale of 5 (scores considered medium/high). Therefore, we can assume that the team knowledge management processes are applied in satisfactory levels at all stages of group development, although at a higher level in phase 3/4 (Restructuring/ Realization) - Hypothesis 1, and lower in phase 2 (Reframing) - Hypothesis 2.

\section{Conclusion}

The testing of our hypotheses, to analyze to what extent the different stages of group development differ with regard to the degree with which one applies knowledge management in its various processes, received empirical support, thus supporting the group development model on which we were anchored. More mature and cooperative groups use knowledge management processes to a greater degree $(\mathrm{H} 1)$ and, by contrast, groups where the climate is marked by greater intragroup competition and where its members seek to "gain power" vis-à-vis the others, use such processes to a lesser extent (H2).

At an intervention level our results suggest that managers and leaders of groups and organizations should pay attention to the development of their work teams to gain added value concerning knowledge management. Work teams with a greater degree of maturity, where group processes work effectively both regarding socio-affective and task subsystems, applied in higher levels the knowledge management processes and can be more prepared to deal with the complexity in order to achieve better performance. Therefore, it is important for leaders and managers to stimulate the development of their work teams.

In spite of the relevance of the results - by their innovative, although "exploratory" nature, and by the use of real work teams/groups in organizational context - there are, however, some limitations worth noting. The methodology used, being non-experimental in nature, does not allow us to establish the causal relation between the variables. The cross-sectional 
nature of this study does not allow us to take into account the dynamic aspect of the variables under study. Additionally, the fact that the data has been collected from a single source can lead to common method variance. To mitigate this threat, some procedures were taken, namely: (a) the anonymity of the individuals was protected (Podsakoff, MacKenzie, Lee, \& Podsakoff, 2003); and (b) our results were aggregated at the team level (Conway, 2002). Although the sample used was very large, one of the strengths of this study, especially when compared to most other studies with teams, the extrapolation of results must be carried out carefully - the data in this study come only from one organization which has very specific characteristics and the unbalanced distribution of the teams in the group development phases may have influenced some results. Another limitation of this study relates to the fact of it having used only perceptive measures.

We reaffirm the need to enrich the work done: integrating new variables (e.g., organizational variables, or external factors affecting the organization); testing on other teams the pattern of results found in the present study, in order to deepen and to consolidate knowledge concerning both the knowledge management processes and the team development; using other methods of data collection (e.g., observation); collecting data from other sources (e.g., from the team leaders) and conducting longitudinal studies or case studies where it would be possible to monitor, systematically and continuously, over a period of time, not only the use of team knowledge management processes, but also the group development itself.

\section{References}

Alferes, V. (1997). Investigação científica em psicologia: Teoria e Prática. Coimbra: lmedina.

Ancona, D., \& Caldwell, D. (1992). Bridging the boundary: External activity and performance in organizational teams. Administrative Science Quarterly, 37, 634-665.

Argote, L., Ingram, P., Levine, J., \& Moreland, R. (2000). Knowledge transfer in organization. Organizational Behavior and Human Decision Processes, 82(1), 1-8.

Argote, L., McEvily, B., \& Reagans, R. (2003). Managing knowledge in organizations: An integrative framework and review of emerging themes. Management Science, 49(4), 571-582.

Bales, R. F. (1950). Interaction process analysis: A method for the study of small groups. Chicago: University of Chicago Press.

Barney, J. B. (1991). Firm resources and sustained competitive advantage. Journal of Management, 17(1), 99-120.

Bresman, H. (2012). Inter-team knowledge sharing: The variegated effects of context and when lobbying can help. Academy of Management Proceedings, 1,1 .

Brown, J., \& Utterback, J. (1985). Uncertainty and technical communication patterns. Management Science, 31(3), 301-311.

Brown, T. (2006). Confirmatory fator analysis for applied research. New York: Guilford.

Burke, M. J., \& Dunlap, W.P. (2002). Estimating interrater agreement with the average deviation index: A user's guide. Organizational Research Methods, 5(2),159-172.
Burke, M. J., Finkelstein, L.M., \& Dusig, M.S. (1999). On average deviation indices for estimating interrater agreement. Organizational Research Methods, 2(1), 49-68.

Buzalo, G., \& Wheelan, S. (1999). Facilitating work team effectiveness: Case studies from Central America. Small Group Research, 30(1), 108-129.

Cardoso, L. (2003). Gerir conhecimento e gerar competitividade: Estudo empírico sobre a gestão do conhecimento e seu impacto no desempenho organizacional (Tese de doutorado não publicada). Faculdade de Psicologia e Ciências da Educação da Universidade de Coimbra, Coimbra, Portugal.

Cardoso, L., \& Peralta, C.F. (2011). Gestão do conhecimento em equipas: Desenvolvimento de um instrumento de medida multidimensional. Psychologica, 55, 79-93.

Chan, D. (1998). Functional relationships among constructs in the same content domain at different levels of analysis: A typology of composition models. Journal of Applied Psychology, 83, 234-246.

Chang, A., Duck, J., \& Bordia, P. (2006). Understanding the multidimensionality of group development. Small Group Research, 37(4), 327-350.

Cohen, J. (1988). Statistical power analysis for the behavioral sciences (2nd ed.). New York: Academic Press.

Conway, J. M. (2002). Method variance and method bias in industrial and organizational psychology. In S. G. Rogelberg (Ed.), Handbook of research methods in industrial and organizational psychology (pp. 344-365). Oxford: Blackwell Publishing.

Cummings, J. N. (2004). Work groups, structural diversity, and knowledge sharing in global organization. Management Science, 50(3), 352-364.

Dimas, I. (2007). (Re)pensar o conflito intragrupal: Niveis de desenvolvimento e eficácia (Tese de doutorado não publicada). Faculdade de Psicologia e de Ciências da Educação da Universidade de Coimbra, Coimbra, Portugal

Dimas, I. D., Lourenço, P. R., \& Miguez, J. (2008). Conflitos, gestão de conflitos e desenvolvimento grupal: Contributo para uma articulação. Psychologica, 47, 9-27.

Gamero, N., Gonzalez-Romá, V., \& Peiró, J. M. (2008). The influence of intra-team conflict on work teams' affetive climate: A longitudinal study. Journal of Occupational and Organizational Psychology, 81, 47-69.

Garfield, M. J., \& Dennis, A. R. (2013). Toward an integrated model of group development: Disruption of routines by technologyinduced change. Journal of Management Information Systems, 29, 43-86.

Hair, J. F., Anderson, R. E., Tatham, R. L., \& Black, W. C. (2008). Multivariate data analysis (7th ed.). Essex: Pearson PrenticeHall.

Henriksen, L. B. (2001). Knowledge management and engineering practices: The case of knowledge management, problem solving and engineering practices. Technovation, 21, 595-603.

Howell, D. C. (2013). Statistical methods for psychology (8th ed.). Belmont, CA: Wadsworth, Cengage Learning.

Huang, C. (2009). Knowledge sharing and group cohesiveness on performance: an empirical study of technology R\&D teams in Taiwan. Technovation, 29, 786-797. 
Ibrahim, J. G., Chen, M. H., Lipsitz, S. R., \& Herring, A. H. (2005). Missing-data methods for generalized linear models: A comparative review. Journal of the American Statistical Association, 100, 332-346.

Ingram, P., \& Simons, T. (2002). The transfer of experience in groups of organizations: implications for performance and competition. Management Science, 48(12), 1517-1533.

Jehn, K.A., \& Shah, P.P. (1996). Interpersonal relationships and task performance: An examination of mediating processes in friendship and acquaintance groups. Journal of Personality and Social Psychology, 72, 775-790.

Jones, J. E., \& Bearley, W. L. (2001). Facilitating team development: A view from the field. Group Facilitation, 3, 56-65.

Karriker, J. H. (2005). Cyclical group development and interactionbased leadership emergence in autonomous teams: An integrated model. Journal of Leadership \& Organizational Studies, 11, 54-64.

Kline, R. B. (2011). Principles and practice of structural equation modeling (3rd. ed.). New York: The Guilford Press.

Kozlowski, S. W. J. (2015). Advancing research on team process dynamics: Theoretical, methodological, and measurement considerations. Organizational Psychology Review, 5, 270-299.

Kozlowski, S. W. J., \& Ilgen, D. R. (2006). Enhancing the effectiveness of work groups and teams. Psychological Science in the Public Interest, 7, 77-124

Kuipers, B. S., \& Stoker, J. I. (2009). Development and performance of self-managing work teams: A theoretical and empirical examination. The International Journal of Human Resource Management, 20, 399-419.

Lee, P., Gillespie, N., Mann, L., \& Wearing, A. (2010). Leadership and trust: Their effect on knowledge sharing and team performance. Management Learning, 41(4), 473-491.

Lewin, K. (1951). Field theory in social science. New York: Harper.

Liang, D. W., Moreland, R. L., \& Argote, L. (1995). Group versus individual training and group performance: The mediating role of transactive. Personality and Social Psychology Bulletin, 21, 384-393.

Lourenço, P. R., \& Dimas, I. D. (2011a). O grupo revisitado: Considerações em torno da dinâmica e dos processos grupais. In A. D. Gomes (Coord.), Psicologia das organizações, do trabalho e dos recursos humanos: Contributos para a investigação e intervenção (pp. 133-139). Coimbra, Imprensa da Universidade.

Lourenço, P. R., \& Dimas, I. D. (2011b), From the past to the present: Building workgroups. In J. P. Valentim (Ed.), Societal approaches in social psychology (pp. 195-216). Bern: Peter Lang.

Love, J. H., \& Roper, S. (2009). Organizing innovation: Complementarities between cross-functional teams. Technovation, 29, 192-203.

Marques, L. C. (2010). Desenvolvimento Grupal: Adaptação da EDG-D para o contexto laboral e estudo das suas qualidades psicométricas (Dissertação de mestrado não publicada). Faculdade de Psicologia e de Ciências da Educação da Universidade de Coimbra, Coimbra, Portugal.

Miguez, J., \& Lourenço, P. (2001, Nov.). Qual a contribuição da metáfora "equipa" para a abordagem da eficácia organizacional? Comunicação apresentada no IV Encontro Luso-Espanhol de Psicologia Social, Porto.
Miller, D., \& Shamsie, J. (1996). The Resource-based view of the firm in two environments: The Hollywood film studios from 1936 to 1965. Academy of Management Journal, 39(3), 519-543.

Moreira, J. M. (2007). Dos grupos às categorias sociais: Contributos para a compreensão dos processos de fusões e aquisições de empresas (Tese de doutorado não publicada). Faculdade de Psicologia e de Ciências da Educação da Universidade de Coimbra, Coimbra, Portugal.

Nelson, K. M., \& Cooprider, J. G. (1996). The contribution of shared knowledge to IS group performance. MIS Quarterly, 20, 409-429.

Pinto, A. (2009). Funcionamento interno das equipas de trabalho: Bidimensionalidade, interdependência e desempenho (Dissertação de mestrado não publicada). Faculdade de Psicologia e Ciências da Educação da Universidade de Coimbra, Coimbra, Portugal.

Pinto, N. (2012). A relação entre os fatores liderança, desenvolvimento grupal e eficácia na diade treinador-equipa desportiva (Tese de doutorado não publicada). Universidade da Madeira, Portugal.

Podsakoff, P. M., Mackenzie, S. B., Lee, J., \& Podsakoff, N. P. (2003). Common method biases in behavioral research: A critical review of the literature and recommended remedies. Journal of Applied Psychology, 88(5), 879-903.

Prange, C. (1999). Organizational learning - Desperately seeking theory? In M. Easterby-Smith, L. Araujo, \& J. Burgoyne (Eds.), Organizational learning and the learning organization: Developments in theory and practice (pp. 24-44). London: SAGE Publications Ltd.

Ramalho, A. C. (2008). Emotions and team effectiveness: Driving and restraining forces of a group development (Dissertação de mestrado não publicada). Faculdade de Psicologia e de Ciências da Educação da Universidade de Coimbra, Coimbra.

Ramalho, A. C., Pinto, E., \& Lourenço, P. R. (2012). Emoções nos grupos de trabalho: Uma abordagem desenvolvimental. In C. Carvalho, P. Lourenço, \& C. Peralta (Eds.), A emoção nas organizações (pp. 195-218). Viseu: PsicoSoma.

Rodrigues, A. S. (2008). A definição do conceito de grupo e suas implicações no funcionamento do sistema. O caso das equipas cirúrgicas (Tese de doutorado não publicada). Faculdade de Psicologia e de Ciências da Educação da Universidade do Porto. Porto.

Rousseau, V., Aubé, C., \& Savoie, A. (2006). Le fonctionnement interne des équipes de travail : concepcion et mesure. Canadian Journal of Behavioural Science, 38, 120-135.

Smith, K. K., \& Berg, D. N. (1987). Paradoxes of group life: Understanding conflict paralysis and movement in group dynamics. San Francisco: Jossey-Bass.

St. Arnaud, Y. (1978). Les petits groupes: Participation et communication. Montréal: Les Presses de L'Université de Montréal.

Tabachnick, B. G., \& Fidell, L. S. (2013). Using multivariate statistics (6th ed.), Boston: Pearson Education.

Tuckman, B. W., \& Jensen, M.A.C. (1977). Stages in small group development revisite. Group and Organizational Studies, 2(4), 419-427. 
Wegner, D. M. (1987). Transactive memory: A contemporary analysis of the group mind. In B. Mullen \& G. R. Goethals (Eds.), Theories of group behavior (pp. 185-208). New York: Springer-Verlag.

Wheelan, S. A. (2005). Group processes: A developmental perspective (2nd ed.). Boston: Allyn \& Bacon.
Yu, A.Y., \& Khalifa, M. (2007). A conceptual model for enhancing intra-group knowledge sharing. Sprouts: Working papers on Systems, 7(15), 1-33.

Zárraga, C., \& Bonache, J. (2003). Assessing the team environment for knowledge sharing: an empirical analysis. The International Journal of Human Resources Management, 14(7), 1227-1245.

Zhuge, H. M. J., \& Shi, X. (1997). Analogy and abstract in cognitive space: a software process model. Information and Software Technology, 39, 463-468.

Recebido em 27.12.2016

Primeira decisão editorial em 04.10.2017

Aceito em 04.10.2017 